P-ISSN: 2541-6960; E-ISSN: 2549-8754

Yupa: Historical Studies Journal

Vol. 5 No. 1, 2021 (26-32)

http://jurnal.fkip.unmul.ac.id/index.php/yupa

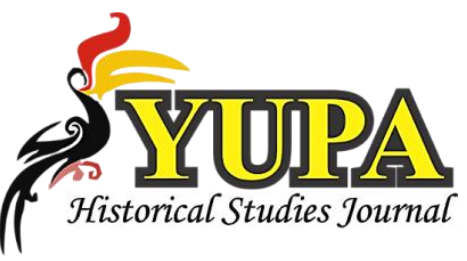

\title{
Pengembangan Bahan Ajar Berbentuk Booklet Materi Masuk dan Berkembangnya Islam ke Indonesia Siswa Kelas X SMA Negeri Tugumulyo
}

\author{
Mita Anggelia \\ STKIP-PGRI Lubuklinggau, Lubuklinggau, Indonesia \\ mitaanggelia22@gmail.com
}

\begin{tabular}{ccc}
\hline Received & Accepted & Published \\
$12 / 10 / 2021$ & $10 / 08 / 2021$ & $21 / 08 / 2021$ \\
\hline
\end{tabular}

\begin{abstract}
This study aims to develop a history booklet about the entry and development of Islam in Indonesia for class X SMA Negeri Tugumulyo according to the 2013 curriculum. This research is development research using a 4-D model which consists of four stages, namely: definition, design, development, and dissemination. Based on the results of the analysis of the assessment by three experts, namely linguists, media experts, and material experts, it shows that the material history booklet of the entry and development of Islam into Indonesia fulfills the valid category with an average score of 3,21. While the results of the analysis of the student assessment sheet consisting of 31 people, it was found that the history booklet of material entry and development of Islam into Indonesia fulfilled the practical category with an average score of 3,60. The result of the $t$-hitung is $7,472$, the significance level is a=0,05 with the degrees of freedom ( $d k / d f) 31$, the t-tabel is 1,697 with a significance of 0,000, which means it is smaller than 0,05, there is a significant relationship, meaning that the history booklet material for the entry and development of Islam into Indonesia is valid, practical, and effective..
\end{abstract}

Keywords: Booklet, Entry and Development of Islam to Indonesian.

Abstrak Penelitian ini bertujuan untuk mengembangkan booklet sejarah materi masuk dan berkembangnya Islam ke Indonesia siswa kelas X SMA Negeri Tugumulyo sesuai dengan kurikulum 2013. Penelitian ini merupakan penelitian pengembangan dengan menggunakan model 4-D yang terdiri dari empat tahap yaitu: pendefinisian (define), perancangan (design), pengembangan (develop), dan pendeseminasian (desseminate). Berdasarkan hasil analisis penilaian oleh tiga ahli yaitu: ahli bahasa, ahli media, dan ahli materi menunjukan bahwa booklet sejarah materi masuk dan berkembangnya Islam ke Indonesia memenuhi kategori valid dengan rata-rata skor 3,21. Sedangkan hasil analisis lembar penilaian siswa yang terdiri dari 31 orang diperoleh bahwa booklet sejarah materi masuk dan berkembangnya Islam ke Indonesia memenuhi kategori sangat praktis dengan rata-rata skor 3,60. Hasil dari thitung sebesar 7,472 taraf signifikan sebesar a=0,05 dengan derajat kebebasan (dk/df) 31, ttabel sebesar 1,697 dengan signifikan sebesar 0,000, yang berarti lebih kecil dari 0,05 maka terjadi hubungan yang signifikan, artinya booklet sejarah materi masuk dan berkembangnya Islam ke Indonesia memenuhi kategori valid, praktis dan efektif.

Kata kunci : Booklet, Masuk dan Berkembangnya Islam ke Indonesia. 


\section{PENDAHULUAN}

Pendidikan merupakan hal terpenting dalam kehidupan manusia, karena melalui pendidikan akan dapat menciptakan manusia yang berpotensi, kreatif dan memiliki ide cemerlang sebagai bekal mencapai masa depan yang lebih baik. Pendidikan di Indonesia pada saat ini telah menggunakan kurikulum 2013 yang disarankan untuk mengintegrasikan budaya bangsa Indonesia agar membangun kehidupan bangsa yang lebih baik di masa mendatang. Mardina (2017:46), mendefinisikan bahwa kurikulum adalah seperangkat rencana dan pengaturan mengenai isi dan buku pelajaran serta cara yang digunakan sebagai pedoman penyelenggaraan kegiatan dalam proses belajar mengajar.

Salah satu pembelajaran yang memungkinkan dikembangkan keaktifan setiap peserta didik ialah proses pembelajaran dengan menggunakan sumber belajar yang menarik yaitu booklet, Menurut Rukmana (2018:2-4), booklet merupakan buku berukuran kecil (A5) dan tipis yang terdiri dari 48 halaman bolak balik, booklet berisi tentang tulisan dan gambar-gambar. Sturktur isi booklet menyerupai buku (pendahuluan, isi, dan penutup), hanya saja cara penyajian isinya jauh lebih singkat dari pada buku.

Berdasarkan hasil observasi awal yang dilakukan di SMA Negeri Tugumulyo pada tanggal 23 Januari 2019 dengan guru mata pelajaran sejarah yaitu Ibu Nazula Erli, S.Pd. diketahui bahwa jumlah siswa kelas X IPS 1 terdiri dari 31 orang, dalam proses belajar mengajar guru menggunakan metode ceramah, dengan menggunakan bahan ajar berupa buku cetak penerbit dari pemerintah dan Lembar Kerja Siswa (LKS), dimana buku paket tersebut sebagai sumber belajar utama sedangkan lembar kerja siswa (LKS) sebagai pendamping. Dari penjelasan guru mata pelajaran sejarah SMA Negeri Tugumulyo bahwa siswa kelas X IPS 1 kurang aktif saat megikuti pembelajaran sejarah karena terbatasnya bahan ajar yang digunakan. Sumber belajar yang mampu meningkatkan hasil belajar peserta didik yaitu berupa booklet sejarah yang nantinya mampu mengaktifkan peserta didik dalam penguasaan materi, sehingga memudahkan guru dalam proses pembelajaran.

Permasalahan berikutnya adalah bahan ajar atau sumber belajar yang digunakan di SMA Negeri Tugumulyo terbatas dan kurang menarik, yaitu berupa buku cetak penerbit dan buku Lembar Kerja Siswa yang jumlahnya terbatas. Sumber belajar yang diharapkan oleh peserta didik di SMA Negeri Tugumulyo adalah sumber belajar yang tidak hanya berisikan tentang tulisan, dan soal-soal saja melainkan berisikan sumber belajar yang memiliki sedikit tulisan disertai gambar-gambar yang jelas sesuai dengan materi, desain dan warna yang digunakan, dan soal-soal sesuai dengan materi, sehingga dapat menarik perhatian dan minat belajar peserta didik. 
Berdasarkan uraian di atas peneliti tertarik untuk melakukan penelitian yang berjudul “Pengembangan Bahan Ajar Berbentuk Booklet Pada Materi Masuk dan Berkembangnya Islam ke Indonesia Siswa Kelas X SMA Negeri Tugumulyo.

\section{METODE}

Penelitian ini dilakukan pada kelas X (sepuluh) SMA Negeri Tugumulyo yang terletak di G1 Mataram Kec. Tugumulyo, Kab. Musi Rawas, Provinsi Sumatera Selatan dengan pertimbangan status sekolah terakreditasi A dan sudah menggunakan Kurikulum 2013. Penelitian ini dilaksanakan pada semester genap tahun ajaran 2019/2020. Jenis penelitian ini merupakan penelitian pengembangan atau Research \& Development (R\&D) dengan menggunakan pengembangan model 4-D.

Tujuan dikembangkannya bahan ajar booklet dengan materi masuk dan berkembangnya Islam ke Indonesia ini memudahkan guru dalam menyampaikan materi kepada siswa dalam proses pembelajaran dan membantu siswa dalam memahami materi supaya aktif dan tidak bosan dengan pelajaran sejarah. Teknik analisis data yang digunakan dalam penelitian ini adalah, wawancara, angket dan tes untuk melihat kevalidan, kepraktisan, dan keefektifan booklet.

\section{Analisis Kevalidan Booklet}

$\bar{V}_{=} \frac{\sum_{i=1}^{m} V_{i}}{n}$

(Modifikasi dari Tanjung \& Nababan, 2018:64)

Keterangan:

$\mathrm{Vi} \quad=$ Skor rata-rata seluruh aspek

$\sum \mathrm{x} \quad=$ Skor seluruh aspek

$\mathrm{n} \quad=$ Banyaknya butir pertanyaan

Kriteria Kevalidan Booklet

\begin{tabular}{cc}
\hline Nilai & Kriteria \\
\hline$V>3,4$ & Sangat Valid \\
\hline $2,8 \leq V \leq 3,4$ & Valid \\
\hline $2,2 \leq V \leq 2,8$ & Cukup Valid \\
\hline $1,6 \leq V \leq 2,2$ & Kurang Valid \\
\hline$V \leq 1,6$ & Sangat Tidak Valid \\
\hline (Modifikasi dari Yuliana, 2017:63)
\end{tabular}

\section{Analisis Kepraktisan Booklet}

$\overline{\mathrm{X}}_{=} \frac{\sum_{\mathrm{i}=1}^{m} \mathrm{Xi}}{n}$

(Modifikasi dari Tanjung \& Nababan, 2018:64) 
Keterangan:

$X \quad=$ Skor rata-rata seluruh aspek

$X \mathrm{i} \quad=$ Skor seluruh aspek

$\mathrm{n} \quad$ = Banyaknya butir pertanyaan

\begin{tabular}{cc}
\multicolumn{2}{c}{ Kriteria Kepraktisan Booklet } \\
\hline Nilai & Kriteria \\
\hline$X>3,4$ & Sangat Praktis \\
\hline $2,8 \leq X \leq 3,4$ & Praktis \\
\hline $2,2 \leq X \leq 2,8$ & Cukup Praktis \\
\hline $1,6 \leq X \leq 2,2$ & Kurang Praktis \\
\hline$X \leq 1,6$ & Sangat Tidak Praktis \\
\hline \multicolumn{2}{c}{ (Modifikasi dari Yuliana, 2017:63) }
\end{tabular}

\section{Analisis Keefektifan Booklet}

Nilai $=$ jumlah skor yang diperoleh $\times 100$

Jumlah skor ideal

Siswa dinyatakan tuntas apabila nilai yang diperoleh di atas 62 (KKM).

Kriteria Efektif Booklet

\begin{tabular}{cc}
\hline Nilai Akhir & Kategori \\
\hline $81-100$ & Sangat Baik \\
\hline $61-80$ & Baik \\
\hline $41-60$ & Cukup \\
\hline $21-40$ & Kurang Baik \\
\hline $0-20$ & Sangat Kurang Baik \\
\hline
\end{tabular}

\section{HASIL DAN PEMBAHASAN}

\section{Tahap Pendefinisian (define)}

Di SMA Negeri Tugumulyo sudah menggunakan kurikulum 2013. Dari hasil observasi yang dilakukan diketahui bahwa permasalahan yang timbul dalam pembelajaran sejarah adalah alam proses belajar mengajar guru hanya menggunakan metode ceramah, dan menggunakan bahan ajar berupa buku cetak penerbit dari pemerintah dan Lembar Kerja Siswa (LKS) yang terbatas. 
Analisis ini sangat penting dilakukan pada awal perencanaan dengan memperhatikan ciri, pengalaman secara perorangan baik secara individu maupun kelompok. Kumpulan prosedur untuk menentukan isi dalam satuan pembelajaran. Analisis tugas dilakukan dengan merinci isi booklet dalam bentuk garis besar. Pengidentifikasian konsep-konsep utama yang tercakup dalam pembelajaran. Tujuan ini untuk mengetahui kemampuan siswa dalam memahami pembelajaran. Merupakan dasar perancang perangkat pembelajaran yang tercantum pada kompetensi dasar. Perumusan ini dilakukan dengan mengkonversikan hasil analisis tugas dan analisis konsep menjadi tujuan pembelajaran.

\section{Tahap Perancangan (design)}

Penyusunan tes berdasarkan hasil penyusunan tujuan pembelajaran menjadi tolak ukur kemampuan siswa berupa produk, proses, dan psikomotor, selama dan setelah kegiatan proses belajar mengajar berlangsung. Media dapat diartikan sebagai perantara atau pengantar pesan dari pengirim pesan ke penerima pesan. Pemilihan media diharapkan sesuai dengan isi materi pembelajaran yang diajarkan. Dilakukan dengan mengadaptasi perangkat yang sudah ada atau dengan cara mengkaji dari referensi-referensi yang relevan. Dalam tahap desain awal perangkat pembelajaran, kegiatan utamanya adalah penulisan, penelaahan, dan pengadaptasian perangkat.

\section{Tahap Pengembangan (develop)}

Tujuan dari tahap ini adalah untuk mendapatkan masukan, kritik, dan saran dari dosen pembimbing dan ahli/pakar sebagai validator tentang kebahasaan, desain, dan materi mengenai booklet.

\begin{tabular}{ccccc}
\hline Validator & $\begin{array}{c}\text { Jumlah Butir } \\
\text { Pertanyaan }\end{array}$ & Skor yang diperoleh & Rata-rata Skor & Kriteria \\
\hline Ahli Bahasa & 10 & 30 & 3,0 & Valid \\
\hline Ahli Media & 10 & 31 & 3,1 & Valid \\
\hline Ahli Materi & 12 & 42 & 3,5 & $\begin{array}{c}\text { Sangat } \\
\text { valid }\end{array}$ \\
\hline jumlah & 32 & 103 & 3,21 & Valid \\
\hline
\end{tabular}

Rata-rata Skor Validator

Uji coba ini dilakukan oleh 6 siswa kelas X IPS.1 SMA Negeri Tugumulyo untuk melihat kekurangan yang masih ada. Hasil dari uji coba ini akan menjadi bahan untuk membuat revisi produk. Tujuan dari uji coba lapangan (field tryout) adalah untuk mengetahui kelayakan booklet yang telah dikembangkan berdasarkan penilaian siswa. booklet yang sudah divalidasi oleh validator perlu disempurnakan lagi agar nantinya relevan dan maksimal sesuai kebutuhan siswa sebagai calon pengguna. 


\section{KESIMPULAN}

Booklet didesain dan dirancang menggunakan aplikasi Miscrosof Word 2010 dengan jenis tulisan Times New Roman ukuran 12-16. Pada cover depan booklet terdapat judul, nama pengarang, logo beserta nama jurusan, dan gambar yang mendukung sesuai pada materi dengan gradasi warna biru dan kuning sehingga membuat booklet telihat lebih menarik. Selanjutnya isi booklet juga terdapat tulisan dan gambar-gambar yang berkaitan dengan materi serta panduan warna yang terang untuk mendukung dan memotivasi siswa untuk belajar. Pada bagian akhir booklet terdapat kesimpulan, saran, evaluasi/latihan, glosarium, daftar pustakan dan data diri pengnulis. Dari desain tersebut booklet kemudian baru di uji kevalidan, kepraktisan dan kefektivannya untuk mendapatkan hasil yang maksimal dan layak untuk digunakan dalam pembelajaran. Kevalidan booklet dilakukan oleh tiga orang ahli yaitu: ahli bahasa, ahli media dan ahli materi dengan memberikan instrumen berupa angket. Dari hasil perhitungan keseluruhan angket para ahli validasi diperoleh 3,21 dengan kategori baik valid.

\section{REFERENSI}

Hamdani. (2011). Strategi Belajar Mengajar. Bandung: CV Pustaka Setia.

Majid, Abdul. (2009). Perencanaan Pembelajaran Pengembangan Standar Kompetensi Guru. Bandung: PT Remaja Rosdakarya.

Mardiana, S. Sumiyatun. (2017). Implementasi Kurikulum 2013 Dalam Pembelajaran Sejarah di SMA Negeri 1 Metro. Jurnal HISTORIA. Vol 5. No 1. Hal 46.

Pralisaputri, K. R. Heribertus, S. \& Chatarina, M. (2016). Pengembangan Media Booklet Berbasis SETS Pada Materi Pokok Mitigasi dan Adaptasi Bencana Alam Untuk Kelas X SMA. Jurnal GeoEco 2. No 2. Hal 147-154.

Rukmana, I. H. (2018). Kelayakan Media Booklet Sub Materi Keanekaragaman Hayati Kelas X SMA. Skripsi Program Studi Pendidikan Biologi FKIP Untan Pontianak.

Septiwiharti, Listya. (2015). Pengembangan Bahan Ajar Berbentuk Booklet Sejarah Indonesia Pada Materi Pertemuan Lima Hari di Semarang Terhadap Minat Belajar Siswa Kelas XI IPS SMA Negeri 1 Semarang Tahun Ajaran 2014/2015. Skripsi Jurusan Sejarah Fakultas Ilmu Sosial Universitas Negeri Semarang.

Tanjung, H.S., \& Nababan, S.A. (2018). Pengembangan Perangkat Pembelajaran Matematika Berorientasi Model Pembelajaran Berbasis Masalah (PBM) untuk Meningkatkan Kemampuan Berfikir Kritis Siswa SMA Se-Kuala Nagan Raya Aceh. Genta Mulia, IX (2), 5670.

Trianto (2007). Model-Model Pembelejaran Inovatif Berorientasi Konstruktivistik. Jakarta: Prestasi Pustaka.

Trianto (2010). Mendesain Model Pembelejaran Inovatif-Progresif. Jakarta: Kencana. 
Yuliana, R. (2017). Pengembangan Perangkat Pembelajaran dengan Pendekatan PMRI pada Materi Bangun Ruang Sisi Lengkung untuk SMP Kelas IX. Jurnal Pendidikan Matematika,6 (1). 60-67. 